\title{
TECCIENCIA
}

\section{PSoC-based embedded system for the acquisition of EMG signals with Android mobile device display}

\author{
Sistemas embebidos basados en PSoC para la adquisición de señales EMG con un dispositivo \\ móvil Android
}

\author{
Javier Andrés Almeida M. ${ }^{1}$, Mayra Alejandra Rodríguez Q. ${ }^{2}$, Juan Sebastián Rubiano L. ${ }^{3 *}$ \\ ${ }^{1}$ Universidad Central, Bogotá, Colombia, Jpachecoa@ucentral.edu.co \\ 2. Universidad Central, Bogotá, Colombia, Mrodriguezq@ucentral.edu.co \\ ${ }^{3}$ Universidad Central, Bogotá, Colombia, jrubianol@ucentral.edu.co
}

\begin{abstract}
In this study, we present the development of an embedded system for the acquisition and processing of Surface Electromyography (EMGs) signals, using Cypress Semiconductor's PSOC technology. With this technology, we achieved a decrease in resource consumption during implementation and in the usage of passive components that are usually part of the filtering, conditioning and acquisition stage, thus allowing for the development of a lightweight portable device. We also developed an application for the Android operating system, where EMG signals sent by Bluetooth can be displayed on a mobile device such as a smartphone or tablet.
\end{abstract}

Keywords: Android, Bluetooth, mobile device, EMGs, PSoC, embedded system.

\section{Resumen}

En este estudio se presenta el desarrollo de un Sistema de embebido para la adquisición y procesamiento de señales de electromiografía de superficie (EMGs), usando la tecnología Cypress de semiconductor PSOS. Con esta tecnología hemos logrado un descenso en la fuente de consumo durante la implementación y el uso de componentes pasivos que son usuales en la etapa de filtración, acondicionamiento y adquisición permitiendo así el desarrollo de un dispositivo ligero portátil. También se desarrolló una aplicación para un sistema operativo Android, donde las señales EMGs son enviadas via Bluetooth, pueden ser mostradas en un dispositivo móvil como un Smartphone o tablet

Palabras Clave: Android, Bluetooth, dispositivos móviles, EMGs, PsoC, Sistema de embebido

\section{Introduction}

Today, the study of Surface Electromyography (EMG) signals is employed for a variety of purposes - for example, studying the average behavior of the electrical activity of a muscle or muscle group, which is widely used to detect muscle fatigue, monitor athletic performance, develop human-machine communication interfaces and control home automation systems for the disabled, thus providing them autonomy and comfort. EMG signal acquisition systems have therefore gained great importance as an input language for systems that perform diverse tasks, whose output is an actuator as well controlled by them.

*Corresponding Author.

E-mail:jirubianol@ucentral.edu.co

Tel: $57+1+3239868$ Ext: 3202
Electromyography (EMG) signals are electrical signals produced by a muscle during the process of contraction and relaxation. These signals can be acquired and employed as a multipurpose tool (monitoring, diagnosing, etc.) and for developing several research projects. Therefore, the implementation of PSoCs technology is of major importance since it manages to integrate the filtering stage, digitization and processing into a single chip, thus reducing resource consumption, size, cost and implementation, leading to a portable prototype.

This paper presents the design and implementation of an electronic system based on PSoCs technology for the acquisition, treatment and processing of two Surface Electromyography (EMG) signal acquisition channels. This

How to cite: Almeida, J.; Rodriguez, M.; Rubiano, J., Psoc based embedded system fot the acquisition of EMG signals with android mobile device display, TECCIENCIA, Vol. 10 No. 18., 14-19, 2015, DOI: http:/dx.doi.org/10.18180/tecciencia.2015.18.3 


\section{TECCIENCIA}

system has a Bluetooth communication interface for sending acquired bioelectrical signals to mobile devices, as well as an application for the Android operating system, where signals can be displayed in real-time and stored in the device's memory.

\subsection{Surface Electromyography}

Surface Electromyography is based on the acquisition of electrical impulses through surface electrodes. These electrodes are placed directly on the skin using a conductive gel on the muscle whose information is desired. The EMGs signals display the activity of various motor units recruited in the execution of a net movement of the studied muscle. EMGs signals are thus used to determine the average behavior of the electrical activity of a muscle or group of muscles, to detect muscular performance under conditions such as muscular fatigue, and/or to monitor muscle performance in athletes [1].

Muscle fibers suffer from transient depolarization (actionpotentials) due to the signals coming from nerve cells, which permit the contractile capacity of the fiber. Muscular activity is registered in the electromyogram, using the actionpotential of the motor-unit which is generated in each muscle after an excitation occurs. In this register, it is possible to distinguish the activation of motor-units, characteristic changes of these variations and relations between units. Taking into account the number of muscular fibers a single motor neuron innervates, one can determine whether a movement is smooth or rough [2]

EMGs signals consist of the summation of motor-unit action-potential trains. The action-potential duration is between 2 and $15 \mathrm{~ms}$ and its amplitude is between $100 \mathrm{pV}$ and $2 \mathrm{mV}$. The morphology of this type of signal depends on the recorded region and the type of electrodes to be used [3].

\subsection{PSoC Technology}

The PSoC family corresponds to Mixed-Signal Array with On-Chip Controller devices. These microcontrollers have been designed to replace multiple traditional MCUs with a single low-cost programmable device. PSoCs include both analog and digital configurable blocks, configurable with Cypress PSoC Designer software [4]. PSoC CY8C29466 is an 8-bit microprocessor, manufactured by Cypress Semiconductor ${ }^{\circledR}$ and with a Harvard architecture, capable of operating at a frequency of up to $24 \mathrm{MHz}$.

\subsection{Android Operating System}

Android is a mobile operating system based on Linux, and along with middleware applications, is designed to be used on mobile devices like smartphones, tablets, Google TV and other devices. The system was developed by Open Handset Alliance, which is led by Google. Android has the advantage of being an open code system, which allows for having more than 800,000 apps on the market [5], most of them free. It allows multitasking, yet this could at times be a disadvantage, since many tasks do not close down after the user finishes using them, thereby consuming memory and rapidly depleting the device's battery. It is for this reason that an additional application that takes care of this function is needed. There are many tools that have facilitated the development of applications for Android. Among these is AppInventor, developed by Google, which is based on graphical programming language with block diagrams.

\section{Methodology}

\subsection{Design and Implementation}

The designed and implemented embedded system can be seen in Figure 1

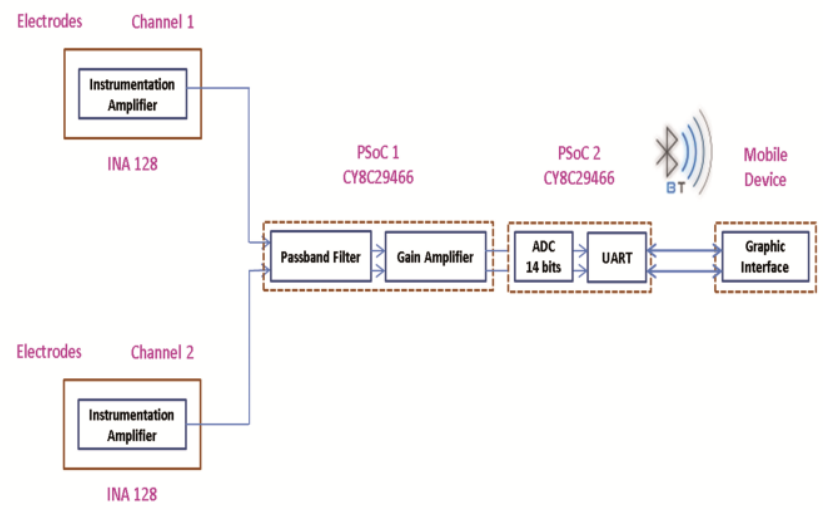

Figure 1 Block diagram of the developed system.

For the present research, self-adhesive $\mathrm{Ag} / \mathrm{AgCl}$ electrodes were used to acquire EMGs signals with an amplitude of between $10 \mathrm{pV}$ and $2 \mathrm{mV}$. To achieve this, we used a INA128 biomedical instrumentation amplifier manufactured from Texas Instruments ${ }^{\circledR}$, which has a CMRR of $120 \mathrm{~dB}$, necessary to acquire such signals. Since EMG signals are within a range of $20 \mathrm{~Hz}$ and $500 \mathrm{~Hz}$ [3], a band-pass filter for both channels of the EMGs was designed and implemented on the PSoC CY8C29466 of the family 1.

The module employed to filter the EMG signal was BPF4, which refers to a fourth order Butterworth bandpass filter. Here, requirements in the frequency domain such as bandwidth, filter gain, center frequency of operation and required filter type (Butterworth, Bessel, Chebyshev and Gaussian) are configured by software. Figure 2 shows the configuration window of the filter and Equations (1) and (2) show the calculations necessary for its proper design. 


\section{TECCIENCIA}

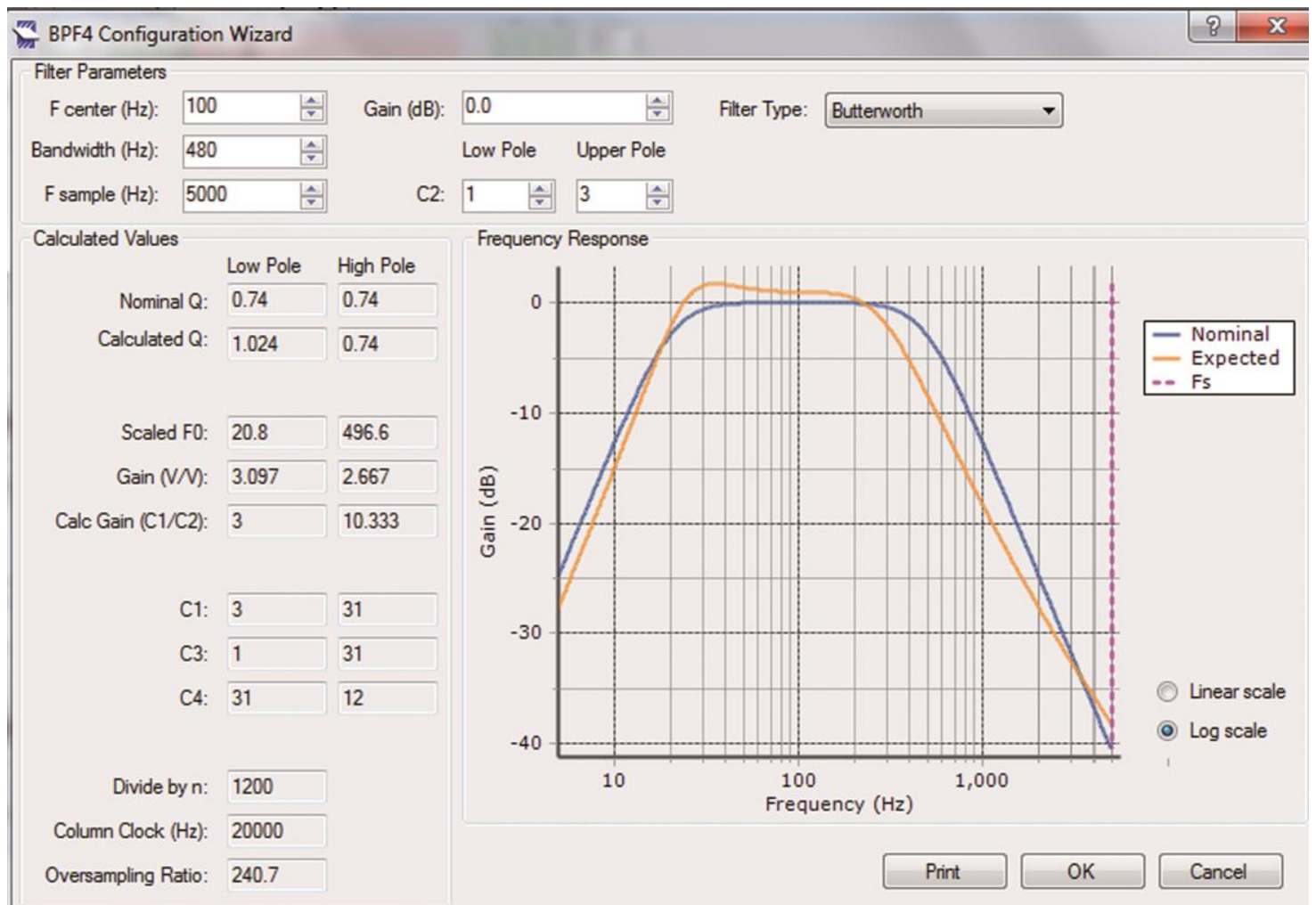

Figure 2 Configuration assistant of the band-pass filter

$\mathrm{BW}=\mathrm{FH}-\mathrm{FL}$

$\mathrm{BW}=500 \mathrm{~Hz}-20 \mathrm{~Hz}$

$\mathrm{BW}=480 \mathrm{~Hz}$

Where:

$B w=$ Bandwidth

$F H=$ Higher Frequency of the filter

$F L=$ Lower Frequency of the filter

$\mathrm{Fc}=\sqrt{F_{H} * F_{L}}$

$\mathrm{Fc}=\sqrt{500 * 200}$

$\mathrm{Fc}=100 \mathrm{~Hz}$

Now, center frequency was calculated as follows:

Where:

$F_{c}=$ Center Frequency

$\mathrm{FH}=$ Higher Frequency of the filter

$F L=$ Lower Frequency of the filter

We employed the ADC Delta-Sigma integrated in the PSoC, in which the sampling frequency of $2 \mathrm{Khz}$ was configured according to the bandwidth of the signal and the sampling with 14-bit resolution. Wireless communication using the Bluetooth module and the mobile device was made via asynchronous serial communication with the UART module of the PSoC at a speed of $115.200 \mathrm{bps}$.

Data sent are displayed in an application designed with the AppInventor tool, which consists of three screens, permitting the user to effortlessly interact with the device. Figure 3 shows the startup screen and the application's connection options.
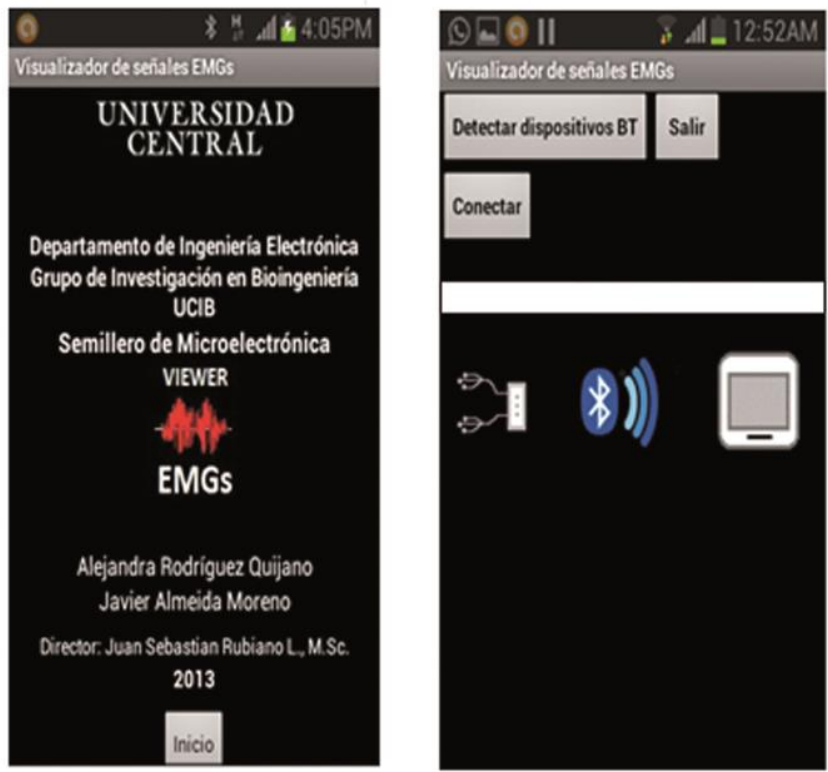

Figure 3 Startup screen and connection options of the application developed for Android. 


\section{TECCIENCIA}

The third screen displays signals in a panel and has the Channel 1 and Channel 2 buttons, configured so that they send a character via Bluetooth which is received by the PSoC through the UART and thus enables an integrated analog multiplexer. The aim is to provide the user with the ease with which to choose which of the two channels of implemented EMG signal acquisition he/she wants to display in the application. Further, the capture button enables the user to save the image that is currently being displayed in the application so it can be consulted when needed. The display screen is shown in Figure 4
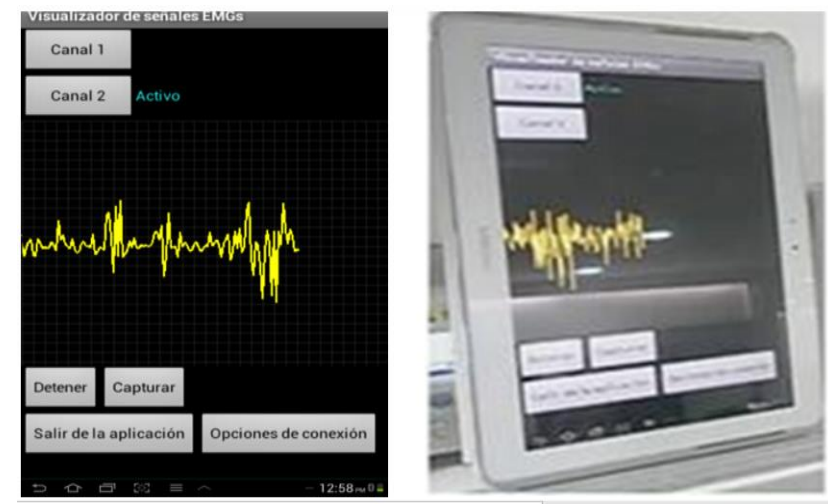

Figure 4 Display of the EMGs signals in the mobile device application

\section{Results and Discussion}

Considering that the signal is being digitalized and sent by Bluetooth, as well as being displayed at different frequencies, we shall proceed to compare the PSoC acquisition and filtering stages with other EMG signal acquisition devices, such as the KL700. For this purpose, we use National Instruments ${ }^{\circledR}$ Labview software and a VI interface designed to acquire the signal with the DAQ6008 card, which displays the signal and stores data in a plain text file, used to create graphics in Excel, as shown in Figure 5 and Figure 6 respectively.

Two net movements involving the flexor carpi radialis muscle are chosen, corresponding to flexion $(\mathrm{F})$ and abduction $(\mathrm{P})$, in a combination of four movements, as shown in Table 1

Table 1 Movements for the flexor carpi radialis muscle group

\begin{tabular}{|c|c|c|}
\hline Movement & Flexor Carpi radicalis musde & Masseter Musde \\
\hline 1 & PPFF & IIDD \\
\hline 2 & FFFP & DDDI \\
\hline 3 & PPPP & IIII \\
\hline 4 & FFFF & DDDI \\
\hline 5 & FFPP & IDDD \\
\hline 6 & PFFF & IIID \\
\hline 7 & PPPF & IDID \\
\hline 8 & PFPF & DIDI \\
\hline 9 & FPFP & DIID \\
\hline 10 & FPPF & IDDI \\
\hline 11 & PFFP & DIII \\
\hline 12 & FPPP & DDID \\
\hline 13 & FFPF & IIDI \\
\hline 14 & PPFP & DIDD \\
\hline 15 & FPFF & IDII \\
\hline 16 & PFPP & \\
\hline
\end{tabular}

The graphics obtained show the previously indicated movements, acquired for the KL700 equipment and the PSoC acquisition system.

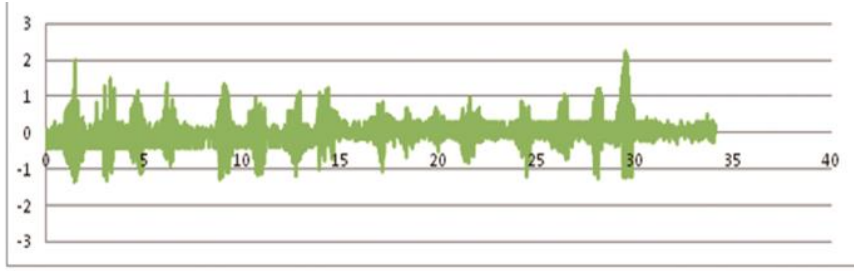

Figure 5 Combination of movements for the flexor carpi radialis muscle group with KL700.

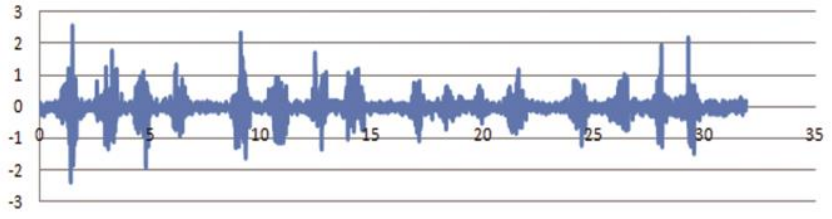

Figure 6 Combination of movements for the flexor carpi radialis muscle group with PSoC.

In the two acquired graphics shown above, it is possible to identify the movement, whether it is $\mathrm{P}$ or $\mathrm{F}$, according to the amplitude and duration of the pulse.

With the patterns of movement mentioned above, the acquisition of the EMGs signals was performed with the developed prototype (see Figure 9) and its display on the Android application. Figure 7 and Figure 8 show the images captured and stored within the mobile device.

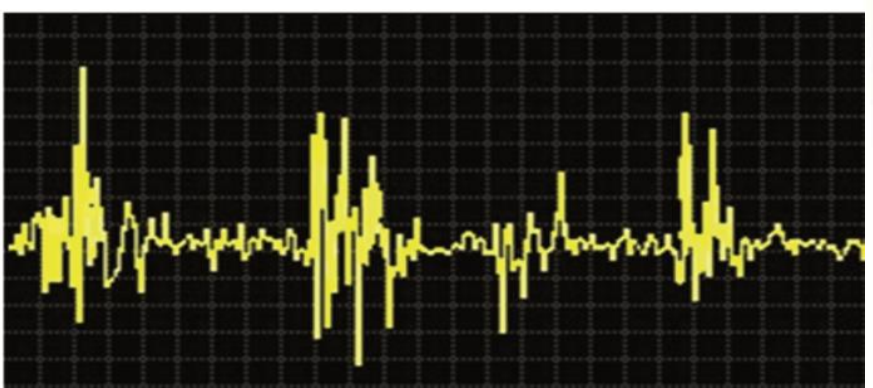

Figure 7 EMG signal of the flexor carpi radialis muscle group (movement PPFF) displayed on the mobile device.

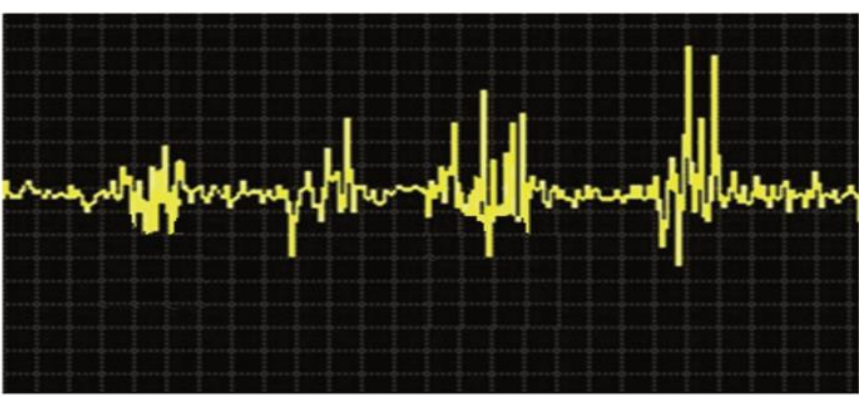

Figure 8 EMG signal of the flexor carpi radialis muscle group (movement FFPP) displayed on the mobile device 


\section{TECCIENCIA}

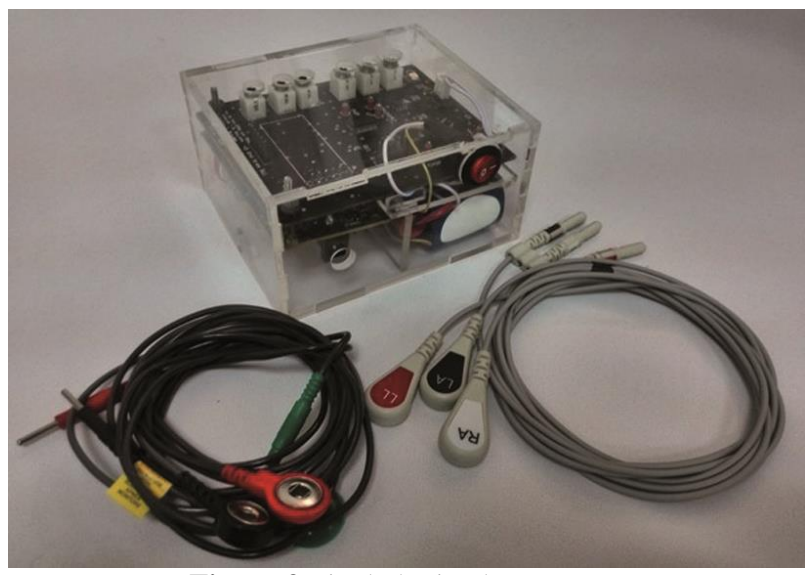

Figure 9 Final obtained prototype.

Since the developed embedded system integrates multiple resources, the blocks to be implemented were divided in two PSoCs.

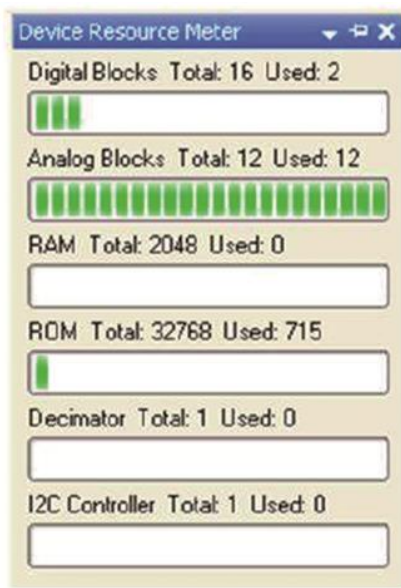

(a)

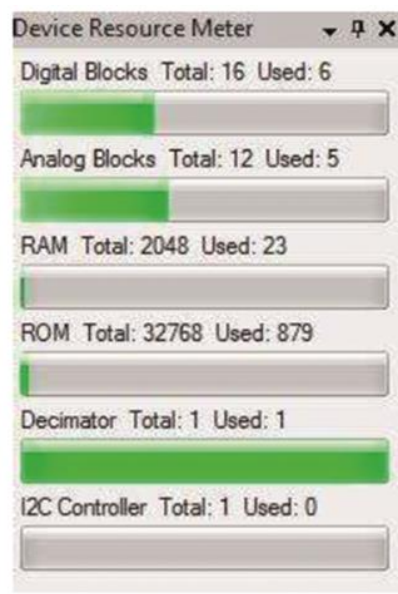

(b)
Figure 10 shows the consumption of resources required during the implementation of the band-pass filter, the analog-todigital conversion and the transmission/reception of the serial data.

One of the most important criteria considered in designing the device was the requirement for user safety. To this end, we consulted Colombian Standard NTC-IEC 60601-1: Equipos Electromédicos parte I. The device was hence classified as portable equipment, with general safety requirements according to section 3 - Protección contra los riesgos de descargas eléctricas:

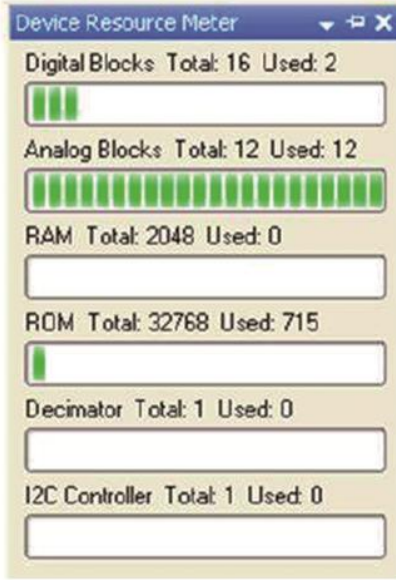

(a)

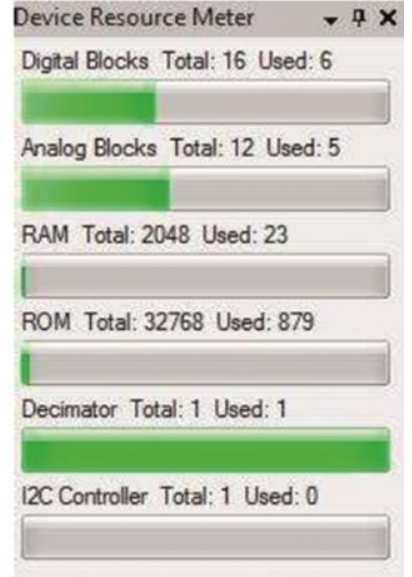

(b)
Figure 10 Resource consumption of the two PSoCs implemented, one for the filtering stage (a) and the other for the analog-to-digital conversion and the transmission/reception of serial data (b).

The Android application for visualizing images was not conceived of for performing diagnosis. In this first stage, the aim is only to capture and display the EMG signal of one or another channel. With this in mind, with the images stored on the mobile device it is possible to recognize the signals via observation and to determine movement type by its amplitude and relation with observed noise.

The PSoC has many advantages due to its integration of analog and digital tools. It is necessary to consider the configuration of each module and their required parameters in order for them to work, especially the oscillator and the frequency dividers needed for each application. This advantage allows for the integration of the entire filtering stage and the processing in a single chip.

For the data transmission stage, the sampling frequency that must be used for functional requirements is $2 \mathrm{KHz}$, which means that every $0.5 \mathrm{~ms}$ data are being sent. To guarantee data acquired was received and displayed in real-time, the Bluetooth block in charge of this function, which is the Clock module, needs to be synchronized and needs to review the data, which comes in twice as fast as the time in which it is sent. This means Clock needs to work with a time interval of $0.25 \mathrm{~ms}$. However, the AppInventor tool does not allow this value to be established, since $1 \mathrm{~ms}$ is the minimum configurable value. We therefore devised a solution not limited by the tool, consisting of the implementation of an interruption in the PSoC, controlled by a timer, so that the sampling frequency is not affected and data can be sent every $20 \mathrm{~ms}$. Thus, the Clock interval was set in the application as $10 \mathrm{~ms}$, synchronizing the PSoC with the application.

We suggest for future studies using Java Native Android or another development tool with more functions, since the AppInventor tool, despite its many advantages, such as the ease of programming and simulation, has a major disadvantage the limited management of the other functions of the 


\section{TECCIENCIA}

components, different to those already established in each block, for sturdier applications. The benefits of this tool are not enough.

\section{Conclusions}

The designed device manages to capture, digitalize and process, through two input channels, the EMG signal, thus reducing the amount of passive components and integrating many of the signal filtering and conditioning stages onto a single chip employing PSoC technology.

The correct positioning of the electrodes and preparation of the signal-recording zone are crucial for proper acquisition.

The manufacture and assembly of the whole embedded system using surface-mount PCB technology enabled the considerable reduction of the size of the final prototype.

The developed system has the option of reprogramming its configuration, thanks to $\mathrm{PSoC}$ resources, and can be implemented to process or visualize other bioelectric signals as ECG, EOC, and EEG, among others.

\section{References}

[1] I. Cifuentes G., «Diseño y construcción de un sistema para la detección de señales electromiográficas,» UADY. Facultad de Matematicas, Merida, 2010

[2] R. Barea Navarro, «Electroneurografía,» Universidad de alcalá. Departamento de Electrónica, Alcalá.

[3] S. Fonseca Gonzales and D. Vanegas Barreto, "Interfaz hombremáquina utilizando señales electromiográficas de musculo masetero. Tesis," Universidad Central, Bogotá, 2007.

[4] C. perform, «Programmable System on Chip,» Cypress, [En línea]. Available: http://www.cypress.com/psoc/.

[5] G. Ojeda and A., "Google Play Supera a la App store con 800.000 aplicaciones disponibles," 10 Jan 2013. [Online]. Available: http://andro4all.com/2013/01/google-play-supera-app-store. 